\title{
Aplikativni vidiki politične geografije v planiranju integracije in razvoja kontaktnih prostorov
}

\author{
Milan Bufon \\ Dr., Oddelek za geografijo, Filozofska fakulteta, Univerza v Ljubljani, \\ Aškerčeva 2, 1000 Ljubljana, Slovenija \\ e-mail:mixe@iol.it
}

\section{Izvleček}

Članek obravnava sodobne vidike političnogeografskih obravnav ter njihove aplikativnosti pri proučevanju konvergentnih in divergentnih družbenih in prostorskih fenomenov. Analizira problematiko interpretiranja meja ter teritorialnosti, še posebno po geopolitičnih transformacijah $\vee$ Evropi ter $\vee$ luči ustvarjanja nove političnogeografske podobe kontinenta in $v$ njem potekajočih integracijskih procesov. $\vee$ nadaljevanju prikazuje pojave in probleme razvoja $v$ evropskih kontaktnih prostorih, ki jih opredeljujejo obmejni status in prisotnost jezikovnih manjšin.

Ključne besede: Politična geografija, evropski in slovenski kontaktni prostori, politične in kulturne meje, družbena integracija, čezmejno sodelovanje

\section{Perspectives For Applied Political Geography In Planning Integration And Development Of Contact Areas}

\begin{abstract}
The article deals with modern aspects of political geography and their applicability in the research of convergent and divergent social and spatial phenomena; first, analysing the re-interpretation of borders and territoriality - especially in the light of European geo-political transformations and the formation of a new geo-political portrait of the European continent and its integration processes - and continuing with a description of phenomena and problems concerning the development of European contact areas, which are determined by their border status, the presence of language minorities.
\end{abstract}

Key words: Political geography, European and Slovene contact areas, political and cultural borders, social integration, cross-border co-operation 


\section{UVOD: PONOVNO ODKRIVANJE IN INTERPRETI- RANJE MEJA TER TERITORIALNOSTI V SODOBNI POLITIČNI GEOGRAFIJI}

Politična geografija se srečuje s problemi in procesi, ki izhajajo iz različnih razmerij med družbo in prostorom, pri čemer se posamezne družbene skupine navezujejo na svoj prostor in razvijajo različne družbene meje in kulturne pokrajine, ki so v preteklosti bile in ostajajo še danes podlaga za nastanek in razmejevanje političnih prostorov: prvenstveno držav, a tudi pod-državnih regionalnih in lokalnih stvarnosti. Osnova političnogeografskih dogajanj je zato razmerje med sočasno potekajočimi težnjami po družbenem in ekonomskem povezovanju (konvergentni procesi) $\mathrm{v}$ okviru nekih spremenljivih funkcionalnih političnih in prostorskih enotah ter težnjami po družbenem in kulturnem razlikovanju (divergentni procesi) na osnovi historičnih elmentov in navezanosti na različne lokalno-regionalne strukture. Pri tem se odpira vprašanje različnih velikosti teritorialnih enot in družb v izvajanju različnih družbenih funkcij ali v oblikovanju različnih stopenj teritorialnosti ter vprašanje razmerja med centralizacijskimi in decentralizacijskimi procesi v državah. Ta element se nato navezuje na vprašanje neenakomernega razvoja, ki ga lahko obravnavamo na globalni ravni preko državnih sistemov, znotraj državnih sistemov ali celo lokalno. Končno ima poseben geografski pomen tudi sam proces navezovanja družbenih skupin na specifičen prostor, se pravi proces družbene teritorializacije na različnih ravneh ter fenomen teritorialne persistence pri modernizaciji družbenih in političnih sistemov. Ta vidik odpira nato vprašanja različne navezanosti na izvorno družbeno okolje in izvorni prostor ter sploh družbene in prostorske mobilnosti v okviru transformacije lokalnih in regionalnih struktur.

Vsi zgoraj našteti elementi in procesi, ki tvorijo sodobno problemsko politično geografijo izhajajo iz kompleksne in velikokrat protislovne stvarnosti sodobnega družbenega razvoja in njegovih učinkov na prostorske strukture. Ti se nanašajo predvsem na trikotno razmerje med družbo, prostorom in modenizacijskimi vplivi in zadevajo transformacije zapletenega sistema, ki zajema tako prostorsko, kulturno, ekonomsko in politično specifiko posameznih politično-teritorialnih enot kot odnose med temi enotami $\mathrm{v}$ času in prostoru. $V$ tem pogledu ima politična geografija v Evropi, kjer se udejanja nova paradigma »združenosti v različnosti«, izredno pomembno vlogo pri planiranju integracije in razvoja obmejnih oziroma kontaktnih območij (Bufon, 2001a).

Proučevanje konvergentnih in divergentnih družbeno-prostorskih procesov pomeni za Evropo predvsem obravnavo dveh temeljnih problemov oziroma fenomenov: teritorialnosti in meja. Kot so razni proučevalci že poudarili, 
je bila časovno-prostorska matrika $\mathrm{v}$ predkapitalističnem ali predmodernem obdobju odprta: obstajal je le en sam, poznan oziroma obvladan svet, ki je temeljil na skupni civilizaciji in skupni religiji, ves preostali svet pa je bil dojet kot $\mathrm{z}$ barbari poseljen in $\mathrm{z}$ negativnimi vrednotami nasičen prostor (Poulantzas, 1978). Tej začetni fazi je sledilo obdobje modernizacije, za katero je posebno značilen pojav meja in logika politične delitve oziroma ustvarjanja ločenih državno-teritorialnih enot, saj je bila teritorializacija prostora predpogoj za uvajanje nove družbene paradigme, ki se je izražala v uvajanju kapitalstičnega načina proizvodnje, industrializacije, prostorske mobilnosti in družbenokulturne standardizacije v okviru posameznih državnih sistemov. Državnoteritorialne enote pa niso le rezultat nacionalizma ali nekakšne kristalizacije obstoječih družbeno-kulturnih prostorov, temveč slednje tudi same oblikujejo, saj se nacionalne ikone sestojijo iz ozemlja, jezika in kulture (Sack, 1980). S tem nastanejo različni notranji ali "domači" ter zunanji ali "tuji" prostori, in nacionalna pripadnost, državljanstvo, segregacija tistih, ki so opredeljeni kot tujci, in njihovo izključevanje iz državno-nacionalnega življenja so vsi elemnti družbeno-prostorskega sistema oblasti, ki je našla svoj najčistejši izraz v izu-u koncentracijskih taborišč.

Različne ločitvene črte so $\mathrm{v}$ različnih obdobjih seveda vplivale druga na drugo: politične meje so tako često osnovane po etničnih principih, toda peristenca političnih meja po drugi strani povzroča spreminjanje etnične strukture $\mathrm{v}$ prostoru. Dialektika odnosov med ekonomskimi in političnimi prostori priaša spet drugačen primer spreminjanja meja oziroma cikličnega razvoja sveovne ekonomije, ki se zdaj izraža v oblikovanju političnih imperijev ali širokih družbenih sistemov, drugič pa v njihovi drobitvi zaradi uvajanja novih ekoomskih paradigm. Na "mobilnost" družbenih in še posebno političnih meja je opozarjal že Ratzel, za katerega je meja pomenila "sestoj številnih točk, na kateih se je določeno organsko gibanje zaustavilo". Sam si je to gibanje razlagal z odnosi med družbami ali med spremenjenimi družbeno-ekonomskimi razmerami in državami, ki se, tako kot drugi organizmi, prilagajajo preoblikovanju njihovega družbenega okolja. Seveda pa meje v nikakršnem pogledu ne morejo popolnoma in trajno razmejevati družbenih skupnosti, saj se zaradi številnih družbenih interakcij $\mathrm{v}$ območjih stika dejansko oblikuje nek kontinuum, ki je v prostorskem pogledu toliko obsežnejši, kolikor bolj intenzivni so stiki med družbenima skupinama. V preteklosti so države želele nekako "zacementirati" svojo oblast v okviru lastnega državnega ozemlja in so zato težile k uveljavljanju čim manj prehodnih političnih meja, ki so se zato navezovale na dovolj vidne in obstojne fizične, še najraje orografske meje, kjer to ni bilo mogoče pa so kar same ustvarile nekakšno mejno "nikogaršnjo" zemljo, ki je bila tradicionalno dobro zastražena, manj razvita in zaradi tega tudi večinoma neposeljena. Še tako neprehodne in utrjene mejne pregrade pa niso 
uspele povsem zaustaviti toka čezmejnih družbenih odnosov, kakor nam kažeta primera Kitajskega in Berlinskega zidu, ki ohranjata danes kvečjemu vlogo turističnih atrakcij. Vsekakor je težnjo po fizičnem razdvajanju družbenih skupin in državnih sistemov $\mathrm{v}$ preteklosti spremljala tudi posebna ideologija po principu "cuius regio eius religio", ki je bila usmerjena k nasilni harmonizaciji družbenih in kulturnih prostorov oziroma prekrivanju etničnih ali jezikovnih in političnih meja (Bufon, 1994a). Notranja standardizacija in posledična homogenizacija državnega ozemlja je pravzaprav "izum" francoske revolucije, ki se je nato razširil na preostale evropske države in dobil, še zlasti v prvi polovici 20. stoletja ekstremno podobo etničnega čiščenja, s prisilno asimilacijo ali neposredno s fizičnim odstranjevanjem nezaželjenih oseb. Iz tega časa so znani masovni pregoni in izgoni Grkov, Armencev in Kurdov iz Turčije, Turkov iz Grčije in Bolgarije, kasneje Judov, Poljakov, Nemcev in drugih ljudstev v Nemčiji in Sovjetski zvezi, v najnovejšem času pa se je ista praksa žal ponovila tudi na območju nekdanje Jugoslavije.

Medtem ko je tradicionalni pristop do mejne problematike večinoma obravnaval horizontalne ali politične meje, se je v novejšem času povečal interes za vertikalne ali funkcionalne meje, saj so danes prve $\mathrm{v}$ funkcionalnem neskladju z rastočo decentralizacijo oblasti ter vse bolj intenzivnim mednarodnim sodelovanjem in povezovanjem. Ker so izkušnje iz prve in druge svetovne vojne evropsko javnost izučile, da prave ali pravične meje ne obstajajo, se večina meddržavnih in mednarodnih aktivnosti ne usmerja več v spreminjanje ali prilagajanje mejnih linij sprotnim geopolitičnim razmeram, temveč predvsem njihovemu "mehčanju" in odstranjevanju (Bufon, 1998a). S tem se politične meje v dobršnem delu Evrope ponovno umikajo v ozadje in se pridružujejo številnim drugim linijam, ki označujejo raznolikost kulturnih pokrajin in regij našega kontinenta, a ga ne razgrajujejo $\mathrm{v}$ ločene teritorialne enote. To dejstvo odpira vprašanje teritorialne identitete in koeksistence med različnimi in različno obstojnimi družbenimi in kulturnimi prostori.

Človekova teritorialnost je močno povezana s socializacijo v okviru specifičnih družb in kultur, zaradi česar je izraz ne samo osebne izkušnje, ampak predvsem prevzetega znanja in vedenjskih oblik, zaradi katerih lahko pozitiven odnos do lastne družbene skupine in lastnega prostora na pobudo vladajočih elit in njihove propagandne dejavnosti prerase $\mathrm{v}$ mitološko predstavo $\mathrm{o}$ "sveti domovini" in v odklanjanje zunanjega sveta po načelu "meje mojega jezika so meje mojega sveta" (Bufon, 1996a in 1999). Proces evropske intgracije vnaša $\mathrm{v}$ to etnocentrično oziroma nacionalistično interpretacijo teritorialnosti nedvomno nove dimenzije in perspektive. A ravno zato da bi lahko bila uspešna, se ne sme omejiti na samo strukturno in funkcionalno družbeno-ekonomsko plat, ki predstavlja ogrodje in vzpodbudo za razvoj integrativnih procesov, ampak se mora spustiti tudi na področje družbeno-kulturne sfere, ki 
omogoča neko trajnejšo dispozicijo do mednarodne koeksistence. Za sodobno politično geografijo Evrope je zato zelo pomembno raziskovanje vseh tistih elementov in dejavnikov, ki pospešujejo ali zavirajo integracijske in koeksistenčne prakse, še posebno v tistih okoljih, kjer dejansko prihaja do družbenega in kulturnega stika (Bufon, 1993; Klemenčič in Bufon, 1994).

Razumljivo je torej, da je proučevanje obmejnih lokalnih skupnosti in razmer za današnjo Evropo osrednjega pomena. To se je pričelo že v prejšnjih desetletjih $\mathrm{v}$ okviru poglabljanja odnosa med centri in periferijami, saj se je večina evropskih obmejnih območij spričo preteklih državnih politik uvrščala med periferne in manj razvite predele, hkrati pa so bile $\mathrm{v}$ obmejnih območjih velikokrat prisotne tudi nacionalne in regionalne manjšine. Vse te lokalne skupnosti so $\mathrm{v}$ pogojih povečane decentralizacije oblasti pričele zahtevati priznanje njihove jezikovne in kulturne specifike, a tudi družbene in prostorske vloge $\mathrm{v}$ ohranjanju kulturne pokrajine in spodbujanju čezmejnega povezovanja (Rokkan in Urwin, 1982; Keating in Laughlin, 1997; Bufon, 1998b).

\section{NOVE PERSPEKTIVE V PROUČEVANJU EVROPSKIH KONTAKTNIH PROSTOROV TER DOPRINOS SLOVENSKE SOCIALNE IN POLITIČNE GEOGRAFIJE}

Evropska integracija namreč ne poteka več po istih vzorcih, kakršne so rabile države za notranjo standardizacijo: veliki izziv današnje evropske stvarnosti je ravno v poskusu, da bi družbeno, ekonomsko in politično integracijo izvedla $\mathrm{v}$ pogojih kulturne različnosti in s tem ponudila svetovni javnosti po približno štirih stoletjih tudi nov civilizacijski model, ki bi tržno ali družbeno-ekonomsko globalizacijo ne enačil nujno tudi z njeno družbeno-kulturno varianto $\mathrm{v}$ obliki amerikanizacije in njenega talilnega lonca.

Ta nov izziv in ta nov evropski civilizacijski model bo našel svojo prvo preizkušnjo in možnost operacionalizacije prav v lastnih tako številnih "kontaktnih" prostorih. Tu ne gre toliko za vprašanje meddržavnega stika in urejanja funkcionalnih družbenih, ekonomskih in administrativnih ovir pri prekomejnem pretoku, kolikor za vprašanje stika med različnimi narodi in etničnimi ter jezikovnimi skupinami in ustvarjanja vsebinskih načel koeksistence $\mathrm{v}$ zavarovanju kulturne specifike. Odpravljanje teh poslednjih "meja" bo zahtevalo bistveno revidiranje tradicionalnih, na izključevanju "drugih" in "različnih" utemeljenih etnocentričnih predstav in družbenih vedenj, ki jih je klasični nacionalizem tako dobro poosebljal. Odkrivati in spoznati bo potrebno, da ob narodni ali nacionalni identiteti sočasno obstajajo še različne etnične, regionalne in jezikovne identitete in da meja med temi ni linearna in jasno razpoznavna, temveč oblikuje izrazito kompleksen in "fraktalen" družbeno-kulturni prostor, 
znotraj katerega prihaja do nenehnih izmenjav in prestopov. Toda kljub temu stalnemu "vrenju" na njihovih robovih oziroma v območju medkulturnega stika, ostajajo kulturni prostori ali kulturne pokrajine presenetljivo stabilni in ponujajo neko "longue-durée" ozadje, kateremu se bolj ali manj zavedno ter bolj ali manj uspešno prilagajajo tudi sprotni družbeni prostori.

V takih okoliščinah ljudje tudi po dolgoletnih odtujevalnih postopkih in državnih asimilacijskih praksah ponovno odkrivajo svojo etnično, regionalno in jezikovno identiteto, a vendar se prav zaradi teh ta identiteta ne ujema vselej z dejansko jezikovno rabo, kakor nam dokazujejo primeri keltskih skupnosti na Irskem in Veliki Britaniji ali v naši neposredni bližini primer Beneških Slovencev. To pomeni, da se "objektivno" etnično ali narodno opredeljevanje, ki temelji na krvni ali prostorski izvornosti ne sklada vselej s subjektivnim opredeljevanjem, na katerega lahko vplivajo najrazličnejši dejavniki in je torej tudi zelo variabilno (Nećak Lük, 1996). Še posebno v tradicionalno etnično mešanih urbanih okoljih pa je tudi objektivno opredeljevanje nemogoče, saj se tu praviloma srečujemo $\mathrm{z}$ večgeneracijsko prepletenostjo mešanih zakonov, $\mathrm{v}$ okviru katere je samo od življenjske usode posameznikov odvisna njegova etnična in jezikovna usmerjenost ali obseg prevzema različnih razpoložljivih kulturnih vsebin in elementov. To v razmerah, kjer državno-nacionalni ekskluzivizem in z njim povezana enojezičnost ne predstavlja več dominantnega modela, ni več tako problematična izbira kot v bližnji preteklosti, saj lahko ljudje $\mathrm{v}$ območjih kulturnega stika svobodneje povezujejo znanje in prakso lokalnega ali lokalnih jezikov z znanjem in prakso različnih standardiziranih nacionalnih jezikov, ob katerih se $\mathrm{v}$ zadnjem času uveljavlja tudi mednarodni sporazumevalni kodeks, ki teelji na angleščini (Knudsen, 1996 ; Williams, 1996).

Slovenska socialna geografija je na pobudo prof. Vladimirja Klemenčiča združila klasični strukturno-analitični koncept obravnave manjšinske problematike, ki so ga razvili zlasti slovenski zgodovinarji po drugi svetovni vojni, z dinamičnim, procesiološkim konceptom. Manjšine je zato opredelila kot poseben dejavnik v družbenem, ekonomskem in prostorskem razvoju, ki je tem bolj uspešen, kolikor bolj uveljavlja svojo kulturno specifiko. Slovenski geografi so zato po eni strani izpostavili funkcijo lokalnih skupnosti in narodnih manjšin v okviru družbene integracije med slovenskimi in sosednjimi obmejnimi območji (Klemenčič in Bufon, 1991 in 1994), po drugi strani pa so na konkretnih primerih slovenskih manjšin izdelali nekatere modele etnično-regionalnega razvoja (Bufon, 1987, 1988 in 1992a) ali pa na primerih posameznih manjšin diskutirali nekatera teoretična izhodišča (Bufon, 1991, 1992b, 1994b in 1994c). V ta okvir sodijo končno še poskusi povezovanja manjšinske in regionalne identitete na primeru različnih območij slovenskega etničnega ozemlja (Klemenčič in Zupančič, 1992), medtem ko so se manjšinskih aspek- 
tov dotaknili tudi prispevki, ki so se ukvarjali z novim geopolitičnim položajem Slovenije (Klemenčič, 1992 in 1993; Klemenčič in Genorio, 1993).

Obdelano je bilo tako vprašanje terminologije avtohtonih narodnih manjšinskih skupnosti v povezavi z njihovim statusom ter družbeno in prostorsko funkcijo. V historičnem pogledu termin nacionalne manjšine implicitno opredeljuje te družbene skupine kot povsem identične z matičnim narodom, saj so te predstavljale nekakšen podaljšek matičnega naroda $\mathrm{v}$ sosednjo državo in zaradi tega nemalokrat povzročale mednarodne konflikte in napetosti. Danes se te manjšine spričo družbene integracije v večinsko okolje uveljavljajo kot avtohtone etnične skupnosti z mednarodno razsežnostjo in izvajajo vrsto specifičnih družbenih in prostorskih funkcij, od narodno-obrambnih do regionalnorazvojnih. Obenem je proces modernizacije doprinesel spreminjanje prostorske distribucije etnične manjšine ter etnične strukture klasičnega ali historičnega majšinskega etničnega ozemlja zaradi povečane prostorske mobilnosti prebivalstva in $\mathrm{s}$ tem uveljavil $\mathrm{v}$ prostorskem pogledu širjenje etnično mešanih območij in v družbenem pogledu oblikovanje tako imenovanega etničnega kontinuита $\mathrm{z}$ razkrojem tradicionalne dvodimenzionalne etnične strukture $\mathrm{v}$ stratificirano. Kot posledico tega procesa so opravljene raziskave izpostavile izenačevanje socio-ekonomske strukture znotraj etnično mešanih območij, ovrednotenje kulturnih značilnosti pokrajine ter povečevanje lokalne in regionalne dejavnosti etničnih manjšin in lokalnih skupnosti pri ohranjanju kulturne pokrajine ter medregionalnem in mednarodnem povezovanju.

Podrobneje so bile obdelane tudi faze etno-regionalnega razvoja (Bufon, 1992a), ki gredo od statičnega sožitja dvoje prostorsko zaprtih enot, se pravi agrarnega, etnično homogenega podeželja in predindustrijskih, etnično mešanih urbanih središč, preko faze enosmernih, labilnih inovacijskih procesov industrializacije in kasneje deagrarizacije, ki so z izseljevanjem iz manjšinskega etničnega ozemlja $v$ bližnje zaposlitvene bazene dejansko razširili obseg narodnostno mešanega ozemlja, do faze formiranja prostorsko odprte in stabilne urbane družbe, kjer se brišejo tradicionalne družbene in etnične razlike med mesti in podeželjem, a kjer etnične manjšine dobivajo nove razvojne perspektive. $Z$ vidika ohranjanja etnične identitete je ravno vmesna faza inovacijskih procesov industrializacije in deagrarizacije najbolj kritična, čeprav ne povzroča takojšnjih strukturnih sprememb, a vodi po eni strani $\mathrm{k}$ demografski eroziji avtohtonega manjšinskega ozemlja in v skrajni konsekvenci do propada dela kulturne pokrajine, po drugi strani pa k dokaj konsistentnemu in celo kompatnemu širjenju manjšinskega prebivalstva izven lastnega avtohtonega ozemlja, kar ima spet lahko različne posledice. Depopulacija avtohtonega ozemlja je zaskrbljujoča tudi zato, ker temeljijo manjšinski normativno-varstveni ukrepi po ustaljeni praksi na historičnem teritorialnem principu, se pravi, da so omejeni na avtohtono naseliteno ozemlje, ki ima za pripadnike manjšine obenem pomembno identifi- 
kacijsko vlogo, zaradi česar lahko pomeni umik iz tega ozemlja mnogokrat tudi izgubo lastne kulturne podlage. Po drugi strani pa lahko prav izsejeniška izkušnja $\mathrm{z}$ neposrednim stikom $\mathrm{z}$ drugimi etničnimi skupinami prispeva $\mathrm{k}$ odkrivanju lastne etnične in kulturne "različnosti" in s tem h krepitvi ali celo porajanju narodnostne zavesti. Uveljavljanje "etničnega kontinuuma" tudi v nekdaj etnično homogenem manjšinskem prostoru, ki ga prinaša sodobna družbena urbanizacija s porastom prostorske mobilnosti, pa ne vodi nujno $\mathrm{v}$ asimilacijo pripadnikov manjšinske komponente ali nastop tako imenovanega vindišarstva (Zupančič, 1993 in 1999), saj se s tem oblikuje povsem nov tip etnične formacije, ki ni le rezultat asimilacijskega stapljanja, temveč aktivne etnične integracije. Na tej osnovi se $\mathrm{v}$ etnično mešanih in obmejnih prostorih uveljavlja situacija družbenega multikulturalizma, ki omogoča strpnejše interetnične odnose, a tudi intenzivnejše oblike čezmejne družbene integracije.

$\mathrm{Ob}$ analizi strukturnih in funkcijskih aspektov manjšin v procesu modernizacije ter oblikovanju modelov etničnega in regionalnega razvoja obmejnih in etnično mešanih območij so bila $v$ številnih prispevkih slovenskih avtorjev podrobneje obdelana še vprašanja vključenosti teh skupnosti v prekomejne tokove, ohranjanja identitete $\mathrm{v}$ spremenjenih družbenih in prostorskih razmerah ter stimuliranja večjezične prakse in interetničnih odnosov. Tako po intenzivnosti opravljenih raziskav na področju manjšinske problematike kot po njihovi kvaliteti se je slovenska socialna in politična geografija polnopravno vključila $\mathrm{v}$ mednarodne tokove in $\mathrm{v}$ ta okvir prispevala originalno raziskovalno metodologijo pri proučevanju funkcije lokalnih skupnosti in manjšin $\mathrm{v}$ obmejnih območjih ter kulturnih aspektov prekomejne povezanosti (Klemenčič in Bufon, 1994; Klemenčič, 1994b).

$\mathrm{Ob}$ meji kot izrazito linearnem prostorskem in družbeno-političnem pojavu, ki je v preteklosti igral vlogo politično-strateške izolinije, se je v politični geografiji postopoma uveljavil tudi nov geografski pojem obmejnih območij, saj je bilo očitno, da se mora interes političnih geografov usmeriti k raziskovanju tako širših geopolitičnih aspektov političnih odločitev in posegov v prostor, ki jih uveljavljanje in spreminjanje političnih meja tako dobro reprezentira, kakor družbenih in prostorskih efektov, ki jih imajo meje v dani regionalni stvarnosti (Bufon, 1998c). V prostorskem smislu zato sodobna politična geografija proučuje meje, ker te označujejo teritorialno dimenzijo političnih organizacij in sistemov, a vplivajo tudi na oblikovanje posebnih obmejnih prostorov, ki niso le različni glede na različno naravo politične meje, ampak se tudi spreminjajo glede na premike v mejni lokaciji ter na mejno funkcionalno dinamiko oziroma njeno večjo ali manjšo prepustnost. Pomen geografije obmejnosti je torej zlasti $\mathrm{v}$ tem, da je meje začela obravnavati ne le v sklopu politično-strateških in politično-zgodovinskih obravnav, temveč jih je postavi- 
la v sklop raziskovanja procesov znotraj obmejnih regij in tu prisotnih družbenih prostorov (Bufon, 2001b).

Stopnje mejne propustnosti so seveda različne tako v času kot v prostoru in lahko gredo od zaviranja čezmejnih izmenjav do usmerjanja čezmejnih, še posebno tranzitnih prometnih tokov skozi večje ali manjše število točk, se pravi mejnih prehodov, ali celo do stimuliranja vsestranske čezmejne integracije obmejnega prebivalstva in oblikovanja prave obmejne regije. To pomeni, da je za obmejne prostore pomembno, da $\mathrm{v}$ njih odkrivamo oblike in dejavnike čezmejne povezanosti, hkrati pa so ta območja zanimiva za razumevanje delovanja ovir v družbenem prostoru. Novejše raziskave so ugotovile, da mejni zaviralni efekt ni absoluten, temveč relativen in selektiven: odvisen je v prvi vrsti od stopnje notranje družbene povezanosti obmejnega prostora, $\mathrm{v}$ katerem predstavlja mejna črta najmanjšo oviro socialnim in kulturnim izmenjavam, ki jih ne more povsem zaustaviti niti v primeru izoliranega sožitja dveh zaprtih obmejnih območij (Suarez Villa et al., 1992). Vzporedno s tem je bilo ugotovljeno, da so v obmejnem prostoru medsebojni konflikti obratno sorazmerni s stopnjo medsebojne povezanosti: bolj ko je obmejni prostor integriran, manjše so možnosti porajanja konfliktov.

Ta ugotovitev je povsem $\mathrm{v}$ nasprotju s tradicionalnim političnogeografskim konceptom (Holdich, 1916; Lattimore, 1962), po katerem so "najboljše" tiste meje, ki predstavljajo največjo možno oviro čezmejni komunikaciji, in kaže na razvoj, ki jo je v povojnem obdobju opravila stroka, a tudi proces mednarodnega sodelovanja. Številne raziskave so opozorile na to, da so ravno obmejne regije, $\mathrm{v}$ katerih prebivalstvo obeh strani meje velikokrat izkazuje skupno regionalno pripadnost ali sorodno etnično in jezikovno strukturo, tisti povezovalni člen, ki v najbolj naravni obliki in najbolj učinkovito prispeva $\mathrm{k}$ razvoju čezmejnih odnosov in mednarodne integracije, saj se v okviru teh regij posamezna obmejna območja po eni strani navezujejo na matično državo, po drugi pa predstavljajo zaradi številnih afinitet s sosednjim območjem pravo prehodno cono. Ugotovljeni so bili tako propulzivni in odbojni faktorji pri čezmejnem sodelovanju, na primer (Maier, 1983):

- enako visoko razvit sistem industrijske družbe v obmejnih območjih;

- skupni sistem informiranja ter poznavanje jezika sosednje države;

- pozitivno razmerje do sosedov ter do čezmejnega sodelovanja;

- pomanjkanje prometnih in informacijski čezmejnih zvez;

- neusklajeno planiranje obmejnih območij;

- prilagajanje prebivalstva položaju zaprte meje.

Poleg tega so bili raziskani še nekateri prostorski in družbeni procesi v preoblikovanju obmejnih območij in njihovem prilagajanju mejnemu režimu, elementi funkcionalne povezanosti obmejnih območij ter njihov prostorski 
obseg. Vse te empirične ugotovitve na primeru različnih srednjeevropskih obmejnih območij so nedvomno pripomogle k razvijanju relativno zgodnjih in konsolidiranih konceptov pri nastavljanju funkcionalnih in regionalno-planskih oblik čezmejnega povezovanja, pri katerih je bila geografija močno soudeležena. Na osnovi takih konceptov so bila obmejna območja opredeljena kot poseben tip perifernih regij, v katerih je gospodarsko in družbeno življenje neposredno pod vplivom bližine mednarodne meje.

$\mathrm{Na}$ vsak način so pri oblikovanju intenzivnejših čezmejnih vezi posebnega pomena drobne čezmejne izmenjave. Njihova časovna persistenca se običajno ne sklada s sistemsko-političnimi spremembami, do katerih je prišlo $\mathrm{v}$ obmejnem prostoru: zaradi tega so primeri takšnega "dolgotrajnega" prostorskega in družbenega vedenja posebno opazni v tistih območjih, ki jih je po sorazmerno dolgem obdobju skupnega življenja "razrezala" nova meja oziroma nov mejni potek. $\mathrm{V}$ določenem pogledu je torej opaziti, da se v podobnih primerih obmejno prebivalstvo tendenčno vede skoraj tako, kakor da do razmejitve ne bi bilo prišlo, in skuša na ta način reproducirati ali ohraniti prvotno enoten družbeni oziroma kulturni prostor. Seveda je možnost razvoja takih procesov odvisna od mejnega režima, večje ali manjše propustnosti meje ter večje ali manjše dinamičnosti družbenih procesov ob njej. Toda očitno je, da se sodobne obmejne regije neredko gradijo ravno na starih temeljih skupnih kulturnih prostorov in na bolj ali manj ohranjenih medsebojnih, iz skupne historične tradicije izvirajočih vezi. Nekoliko paradoksalno izzveni sklep, da imajo zato največ možnosti za čezmejno integracijo prav tista obmejna območja, ki so v ne preveč oddaljeni preteklosti doživljala pri politični delitvi tradicionalno enotnega upravnega, kulturnega in gospodarskega prostora največje travme. Na tej osnovi pa je možno ugotoviti ne le stopnjo kulturne, socialne in ekonomske integracije obmejnih regij, temveč je mogoče tudi zelo podrobno analizirati strukturo čezmejnih stikov, ki se prav dobro prilagajajo običajnim družbenim vedenjskim vzorcem, kakršne je odkrivala in razvijala nemška socialnogeografska raziskovalna metoda $\mathrm{v}$ okviru kategorij bivanja in življenja v skupnosti, dela, oskrbe, izobraževanja in preživljanja prostega časa (Klemenčič, 1987).

\section{SKLEP}

Dejansko bi lahko v odkrivanju prostorskega obsega določenih relevantnih družbenih aktivnosti ob meji in preko nje ter v opredeljevanju prostorske funkcije obmejnih socialnih skupin in manjšin zaznali tudi glavni doprinos slovenske geografije k raziskovanju obmejnih območij (Klemenčič in Bufon 1994). Poudarjeno je bilo tako, da imajo obmejna območja in v njih potekajoči 
čezmejni odnosi velik pomen ne samo na področju družbene in ekonomske integracije na meddržavni in medregionalni ravni, ampak tudi $\mathrm{v}$ ohranjanju kulturnih značilnosti in utrjevanju medetničnega sožitja in povezovanja. Ta element obmejnih območij je še posebno zastopan tam, kjer so prisotne nacionalne manjšine, obmejna območja s takimi značilnostmi pa so $\mathrm{v}$ evropskem kontinentu bolj pravilo kot izjema. Zaradi tega srečujemo izrazitejšo predispozicijo po večji čezmejni integraciji v vseh tistih slovenskih obmejnih območjih, kjer žive vsaj na eni strani mejne črte pripadniki avtohtonih manjšin ali priseljenih skupnosti iz sosednjih območij. Na ta potencial lahko nato kot bolj ali manj učinkovit modifikator deluje različna teritorialna in regionalna orientacija teh skupnosti, ki izhaja iz persistence in prepustnosti posameznih mejnih odsekov, ter različna stopnja zaščite in razvoja manjšinskih skupnosti v odgovarjajočih državnih sistemih. Vse to pa odpira v obmejnih območjih vrsto novih aspektov, ki postajajo vse bolj pomembni v procesu evropske integracije, odpravljanja tradicionalnih funkcij političnih meja in uveljavljanja medsebojnega razumevanja $\mathrm{v}$ kulturno tako raznolikem evropskem prostoru.

Politična geografija s svojimi družbenimi, kulturnimi in političnimi aspekti prevzema zato vse bolj pomembno vlogo v procesu humanizacije tradicionalnega geografskega pristopa do vprašanja političnih, a tudi drugih družbenih in kulturnih meja. Ob čezmejnih "makro" transakcijah med mejnimi družbami se vse bolj izpostavljajo tudi "mikro" transakcije na ravni obmejnega prebivalstva in obmejnih območij $\mathrm{v}$ izpolnevanju vsakdanjih življenjskih potreb in prehajanju od konfliktnih do harmoničnih oblik obmejnosti. Ker se mnoge socialne in ekonomske "mikro" transakcije navezujejo na kulturne vezi med obmejnim prebivalstvom in ker ostajajo te vezi relativno stabilne tudi $\mathrm{v}$ pogojih mednarodnih političnih transformacij, opažamo navidez paradoksalno dejstvo, da imajo največ možnosti razvoja v obmejno regijo prav tista obmejna območja, ki so $\mathrm{v}$ nedavni preteklosti doživele največje probleme ob delitvi dotlej enotnih upravnih, kulturnih in funkcionalnih prostorov. Tudi ta vidik je ob drugih vprašanjih proučevanja oblik čezmejne povezanosti doprinesla slovenska geografija obmejnosti. Seveda je treba na teh izhodiščih v slovenski geografiji še marsikaj narediti: poglobiti vprašanje teritorialnega vedenja regionalnih in lokalnih skupnosti ob mejah ter njihove kulturne in prostorske identitete; razširiti raziskovalni interes od funkcionalno bolj povezanih tudi na ostala obmejna območja in odkrivati vzroke slabše čezmejne integracije; sistematizirati in uskladiti raziskovalno delo na najnovejšem in najdaljšem obmejnem sektorju s Hrvaško, a tudi na drugih obmejnih odsekih; preveriti razmerja med družbenim in prostorskim položajem ob političnih in različnih notranjih meja Slovenije; nenazadnje pa tudi temeljiteje razmisliti o novi vlogi Slovenije kot obmejne države med EU in Balkanom iz vidika njene politične in ekonomske geopolitične integracije ter njenih efektov na notranji regionalni 
razvoj. Skratka, zdi se, da utegne biti Slovenija, upoštevajoč njeno dimenzijo in navedene raziskovalne teme, zelo primeren in priročen "laboratorij" za proučevanje obmejnosti, obmejnih odnosov in čezmejnega povezovanja v pogojih ohranjanja kulturne različnosti, kakor tudi njihovih prostorskih vplivov na "nova" in "stara" obmejna območja Srednje Evrope (Bufon 1996b).

Glede uporabnosti političnogeografskih dognanj v planiranju razvoja čezmejnih integracij, moramo poudariti, da danes ustreznejše čezmejno povezovanje ovirata po eni strani pomanjkanje neke bolj profilirane politike slovenske države do njenih tako številnih in značilnih obmejnih prostorov - in to je problem, ki ga bo morala slovenska vlada nedvomno razrešiti pred vstopom v EU po drugi strani pa še ne razrešeno vprašanje regionalizacije oziroma decentralizacije slovenske lokalne uprave, ki razen občinskega in državnega nivoja ne pozna drugih vmesnih oblik. To vprašanje zadeva spremenjen odnos med državo in lokalnimi skupnostmi, v pogledu mednarodnega sodelovanja pa je še zlasti povezano z oblikovanjem čezmejnih upravnih zvez tipa evroregij, čeprav se ga $\mathrm{v}$ javnosti najpogosteje povezuje $\mathrm{z}$ vprašanjem koriščenja evropskih razvojnih skladov. Izhajajoč iz političnogeografske analize bi bilo v Sloveniji glede na tradicionalne upravne delitve in bodoče potrebe po mednarodnem regionalnem povezovanju ter notranji decentralizaciji namreč dovolj »prostora« za dvo-stopenjsko vmesno upravno organiziranost, se pravi tako za »dežele-regije« kot za »pokrajine-province«, saj bi na ta način uspeli kombinirati tako osnovne gravitacijsko-funkcionalne enote kot širše zgodovinsko-kulturne enote, ki temeljijo na hkratni lokalni in regionalni identiteti slovenskega prebivalstva.

Bodoče političnogeografske obravnave Slovenije in njenih obmejnih območij bodo zaradi tega usmerjene ne le v raziskovanje različnih oblik čezmejnega povezovanja, ampak tudi učinkov odprave političnih meja na družbene in prostorske vezi ter tiste institucionalne in upravne ureditve, ki bo obmejnemu prostoru in prebivalstvu omogočala, da bo uspešno razreševal lastne razvojne probleme ob spoštovanju kulturne specifike prostora ter v perspektivi vse večje družbene in prostorske integracije obmejnih območij. Pri tem sta ključnega pomena načrtnejša vladna politika do obmejnih območij in decentralizacija oziroma regionalizacija lokalne oblasti. Žal v Sloveniji še vedno močno pogrešamo tovrstni pristop v planiranju družbenega in prostorskega razvoja, ki bi moral temeljiti tudi na obsežni raziskovalni izkušnji in nezanemarljivih dosežkih slovenske politične geografije pri proučevanju vprašanja teritorialnosti in obmejnosti ter sploh učinkov sočasnega delovanja konvergentnih in divergentnih procesov v slovenskem kontaktnem prostoru. 


\section{Literatura:}

Bufon M., 1987: Regionalni razvoj in narodnostno vprašanje. Geografski obzornik 2, Ljubljana, str. 85-87.

Bufon M., 1988: Sviluppo regionale e sviluppo etnico - il caso degli Sloveni in Italia. V: L'effet frontière dans les Alpes, Tome I. St.Vincent, 1988, str. 54-61.

Bufon M., 1991: Prispevek k sistematizaciji geografskega proučevanja nacionalnih manjšin na primeru Slovencev v Italiji. Geografija v šoli 1, Ljubljana, str. 26-28.

Bufon M., 1992a: Prostorska opredeljenost in narodna pripadnost - Obmejna in etnično mešana območja $\mathrm{v}$ evropskih razvojnih silnicah: primer Slovencev v Italiji. Trst, SLORI.

Bufon M., 1992b: Sedanji evropski razvojni procesi in varstvo manjšin - stari problemi in nove perspektive $v$ luči politične geografije. Geografija $v$ šoli 2, Ljubljana, str. 25-32.

Bufon M., 1993: Elementi obmejnosti in faktorji oblikovanja prekomejnih območij na primeru Slovenije. V: M.Pak (ur.), Geografski aspekti obmejnosti in regionalnega razvoja. Dela 10, Ljubljana, str. 99-109.

Bufon M., 1994a: Regionalizem in nacionalizem. Annales 5, Koper, str. 9-16.

Bufon M., 1994b: Nacionalne manjšine in njihova funkcija $\mathrm{v}$ mednarodnih integrativnih procesih - iluzija ali realnost? V: I.Štrukelj in E.Sussi (ur.), Narodne manjšine danes in jutri. Trst, SLORI, str. 87-95.

Bufon M., 1994c: Manjšine v sodobnih razvojnih procesih - primer Slovencev v Italiji. V: P.Vencelj, V.Klemenčič in S.Novak Lukanovič (ur.), Manjšine v prostoru Alpe-Jadran. Ljubljana, Vlada RS, str. 52-69.

Bufon M., 1996a: Naravne, kulturne in družbene meje. Annales 8, Koper, str. 177-186.

Bufon M., 1996b: Some political-geographical problems of transition in Central Europe. V: F.W.Carter, P.Jordan in V.Rey (ur.), Central Europe after the Fall of the Iron Curtain. Frankfurt, Peter Lang, str. 73-89.

Bufon M., 1998a: Le regioni transfrontaliere nel processo di unificazione europea. V: P.Bonavero in E.Dansero (ur.), L'Europa delle regioni e delle reti. Torino, Utet, str. 126-142.

Bufon M., 1998b: Procesi evropske integracije in ohranjevanje jezika narodnih manjšin. V: I.Štrukelj (ur.), Jezik za danes in jutri. Ljubljana, Društvo za uporabno jezikoslovje, str. 65-76.

Bufon M., 1998c: Borders and border landscapes - a theoretical assessment. V: M.Koter in K.Heffner (ur.), Borderlands and Transborder Regions. Opole-Lodz, str. 7-14. 
Bufon M., 1999: Problematika teritorialnosti v politični in kulturni geografiji. Geografski vestnik 71, Ljubljana, str. 91-103.

Bufon M., 2001a: Osnove politične geografije I-II. Ljubljana, Oddelek za geografijo Filozofske fakultete Univerze v Ljubljani.

Bufon M., 2001b: Geografija obmejnosti, čezmejne regije in oblike čezmejne povezanosti. Geografski vestnik 73, Ljubljana, str. 9-24.

Holdich T.H., 1916: Political Frontiers and Boundary Making. London.

Keating M. in Loughlin J. (ur.), 1997: The Political Economy of regionalism. London, Frank Cass.

Klemenčič V. in Bufon M., 1991: Geographic problems of frontier regions the case of the Italo-Yugoslav border landscape. V: D.Rumley in J.V. Minghi (ur.), The Geography of Border Landscapes. London, Routledge, str. 86-103.

Klemenčič V. in Bufon M., 1994: Cultural elements of integration and transformation of border regions - the case of Slovenia. Political Geography 1, str. 73-83.

Klemenčič V. in Genorio R., 1993: The new state of Slovenia and its function within the frame of Europe. GeoJournal 3, str. 323-335.

Klemenčič V. in Zupančič J., 1992: Regionalizem - nov izziv za geografijo: primer slovenskega etničnega ozemlja. Geografski vestnik 64, Ljubljana, str. 157-168.

Klemenčič V., 1987: Državna meja na območju Slovenije in obmejna območja kot nov geografski fenomen. Razprave in gradivo 20, Ljubljana, str. 57-79.

Klemenčič V., 1992: Geopolitični položaj Slovenije in njena odprtost v Evropo. Geografija v šoli 2, Ljubljana, str. 15-24.

Klemenčič V., 1993: Geopolitični položaj in regionalizem na primeru jugozahodne Slovenije. Annales 3, Koper, str. 203-210.

Klemenčič V., 1994: Funkcija narodnih manjšin v prekomejnem meddržavnem povezovanju in evropski integraciji. V: I.Štrukelj in E.Sussi (ur.), Narodne manjšine danes in jutri. Trst, SLORI, str. 97-107.

Knudsen A., 1996: European ethnic and linguistic minorities in a social anthropological perspective. V: I.Šumi. in S.Venosi (ur.), Večjezičnost na evropskih mejah - primer Kanalske doline. Kanalska dolina, SLORI, str. 17-28.

Lattimore O., 1962: Studies in Frontier History. Paris.

Mackinder H., 1904: The geographical pivot of history. Geographical Journal 23 , str. 421-442.

Maier J., 1983: Grenzen und Raumforschung - eine Problemskizze. Staatsgrenzen und Einfluss auf Raumstrukturen und Verhaltensmuster. Bayreuth.

Nećak Lük A., 1996: Medetnični odnosi v sociolingvistični perspektivi. V: I.Šumi in S.Venosi (ur.), Večjezičnost na evropskih mejah - primer Kanalske doline. Kanalska dolina, SLORI, str. 131-150. 
Poulantzas N., 1978: State, Power, Socialism. London, New Left Books.

Rokkan S. in Urwin D.W., 1983: Economy, Territory, Identity. London, Sage.

Sack R.D., 1980: Conceptions of Space in Social Thought. London, Macmillan.

Suarez-Villa L. et al., 1992: Territorial and border barriers in information and communication networks: a conceptual exploration. TESG 2, Utrecht, str. 93-105.

Williams C.H., 1996: Ethnic identity and language issues in development. V: D.Dwyer in D.Drakakis-Smith (ur.), Ethnicity and Development: Geographical Perspectives. London, Wiley, str. 99-123.

Zupančič J., 1993: Socialnogeografska transformacija in narodna identiteta primer Slovencev na Koroškem. Geographica Slovenica 24, Ljubljana, str. 65-72.

Zupančič J., 1999: Slovenci v Avstriji. Geographica Slovenica 32, Ljubljana, Inštitut za geografijo.

\title{
PERSPECTIVES FOR APPLIED POLITICAL GEOGRAPHY IN PLANNING INTEGRATION AND DEVELOPMENT OF CONTACT AREAS
}

\begin{abstract}
Summary
Political geographers research problems and processes originating from a variety of relations between society and space: societal characteristics and possibilities of development are conditioned by space; and in return, space is re-defined, re-shaped and imbued with value by the society. In addition, an important element for the valorization of space is technology, resulting in an intensification of communication, a higher quality of information, and a more coherent orientation. The expansion of communication and consequently greater exchange of information leads to the expansion of our perception and mastery of the space.

The development of social institutions engaged in cultural and politicaleconomic activities proceeds in accordance with social development. This process takes place in spatial units that are claimed, inhabited, administered, defended and invested in by various social groups. In this way individual social groups interact with their space, which also contributes to their differenttiation and shapes various social boundaries and cultural regions, which in the past were, and today remain, the basis for the birth and demarcation of political spaces: most of all states, but also sub-national regional and local entities. Thus, the basis of political-geographical phenomena is the relation between
\end{abstract}


the co-occurring aspirations for social and economic integration (convergent processes) within variable functional political and spatial units, and aspirations for social and economic differentiation (divergent processes), which are based on historical elements and links with various local-regional structures. As a result, two questions arise: that of different sizes of territorial units and societies engaged in the operation of various social functions and in the formation of different levels of territoriality, and that of the relation between centralisation and decentralisation processes within states. These elements are further linked to the issue of uneven development, which can be dealt with at the global level through national systems, within national systems, and also locally. Special geographical importance is borne by the interaction process of social groups within a specific space, i.e. the process of social territorialisation at different levels and the phenomenon of territorial persistence when modernisation of social and political systems occurs. Moreover, the latter opens the question of different levels of attachment to the original social environment and space, and that of social and spatial mobility within the framework of the transformation of local and regional structures.

As a result of an initiative proposed by Prof. Vladimir Klemenčič, Slovene social and political geographers began dealing with these issues at an early stage, discussing Slovene contact areas in the light of the transformation of border areas and of the social function of local communities and minorities. The object of discussion was various phases of social and spatial transformation and their effects on spatial distribution, social structure and identity of local communities. Terminological problems concerning the definition of local communities in relation to their modified social roles and spatial functions were opened, and the discussion about the dynamics of ethno-regional development and the formation of the inter-ethnic continuum within contact areas was deepened. Thus, the process of social modernisation re-opened the issue of the definition of ethnicity as an element of social and cultural differentiation, and that of the new integrative role of minority communities in border areas. Direct applicative aspects of political-geographical research into these issues had most evidently influenced the planning of an appropriate sociocultural structure of the educational system, in particular different language models in public education, the planning of appropriate methodology, and a dynamic interpretation of data referring to ethnic and language structures, the planning of an appropriate social policy, and most of all the development of co-existential practices between ethnic groups and policies of cross-border cooperation and integration between local communities and national systems. Factors that hinder and those that foster socio-cultural and socio-economic integration were observed, and special emphasis was laid on the significance 
of social integration as a distinctive factor reducing potential social conflict in contact areas.

Furthermore, Slovene political geographers developed a special methodology for the research of the inter-dependence of cross-border local communities. The methodology is based on the analysis of existing borders, the regionalstructural analysis of the border area, and the analysis of the socio-cultural contacts between the border area populations. The latter allows a detailed typologycal partition of the border area and a comparison between different border areas at the national and international levels. Thus, the significance of border areas and relations inter-acting within these were pointed out, not only in terms of the social and economic integration at the international and inter-regional levels but also in terms of the preservation of cultural characteristics and the consolidation of inter-ethnic symbiosis and bonds. These elements are most typical of those border areas where national minorities are present, which on the European continent represent a rule and not an exception. That is why a more explicit predisposition for more intense cross-border integration can be observed in Slovene border areas that neighbour autochthonous minorities or immigrant communities on the other side of the border line. This potential can be subjected to the effects of a more or less efficient modifier of different spatial and regional orientation of these communities, arising from the persistence and permeability of individual border sections, and different levels of protection and development of minority communities in respective national systems. These factors lead to the emergence of a series of new aspects, acquiring increasing importance within the processes of European integration, the abolition of traditional functions of political borders, and the recognition of mutual understanding in the cultural diversity of the European space.

With its social, cultural and political aspects, political geography is becoming increasingly important in the process of the humanisation of the traditional geographical approach to the issue of political, social and cultural borders. Together with the importance of cross-border "macro"-transactions between border area companies, another element contributing to the transition from conflicting to harmonious forms of co-habitation is being pointed out with increasingly frequency: the significance of "micro"-transactions of the border population, that is, providing for their daily needs. A number of these social and economic "micro"-transactions are linked to cultural bonds between the border populations. Since these remain relatively stable despite being subjected to international political transformations, an apparent paradox appears: those border areas which in the recent past experienced the most serious conflicts when united administrative, cultural and functional spaces were divided, have the highest possibilities for development into a border region. On the international scale, due to its size and above stated research topics, Slovenia 
was recognised as a suitable and convenient "laboratory" for the research of border areas, cross-border relations and cross-border integration in conditions preserving cultural diversity, and their spatial impacts on "new" and "old" border areas of Central Europe.

As a result, future political-geographical discussions concerning Slovenia and its border areas will not only be oriented toward the research of various forms of cross-border integration but also effects concomitant to the abolition of political borders on social and spatial bonds, and those institutional and administrative structures allowing the border area and its population to solve their own development problems respecting the cultural specificity of the space, and recognising the growing social and spatial integration of border areas. In this respect, key roles are played by a carefully planned governmenttal policy concerning border areas, and the decentralisation, i.e. regionalisation, of local authority. Unfortunately, Slovenia is not yet experiencing such an approach to the planning of the social and spatial development, which ought to be based on comprehensive research experiences and achievements of Slovene political geography in terms of the research of the issue of territoryality and border areas as well as effects of co-occuring convergent and divergent processes in the Slovene contact area. 